\title{
Plagiarisms, Authorships, AND THE Academic Death Penalty
}

\author{
Rebecca Moore Howard
}

1

n composition studies, most published discussions of student plagiarism proceed from the assumption that plagiarism occurs as a result of one of two possible motivations: an absence of ethics or an ignorance of citation conventions. Some students don't appreciate academic textual values and therefore deliberately submit work that is not their own; others don't understand academic citation conventions and therefore plagiarize inadvertently. Both of these are negative interpretations, postulating an absence-of either ethics or knowledge-in the plagiarist. A few recent studies, though, identify positive motivations for patchwriting, a textual strategy that has traditionally been classified as plagiarism. Patchwriting involves "copying from a source text and then deleting some words, altering grammatical structures, or plugging in one-for-one synonym-substitutes" (Howard 233). Describing the textual strategies of Tanya, a student who in traditional pedagogy might be labeled "remedial," Glynda Hull and Mike Rose celebrate her patchwriting as a valuable stage toward becoming an authoritative academic writer: "we depend upon membership in a community for our language, our voices, our very arguments. We forget that we, like Tanya, continually appropriate each other's language to establish group membership, to grow, and to define ourselves in new ways, and that such appropriation is a fundamental part of language use, even as the appearance of our texts belies it" (152).

These and other studies describe patchwriting as a pedagogical opportunity, not a juridical problem. They recommend that teachers treat it as an important transitional strategy in the student's progress toward membership in a discourse community. To treat it negatively, as a "problem" to be "cured" or punished, would

Rebecca Moore Howard, an assistant professor in the Department of Interdisciplinary Writing at Colgate University, teaches composition, rhetoric, and linguistics. She is at work on Standing in the Shadow of Giants, an extended reflection on the applications of authorship theory to composition pedagogy, to be published by Ablex. With Sandra Jamieson, she is author of The Bedford Guide to Teaching Writing in the Disciplines: An Instructor's Desk Reference (1995).

College English, Volume 57, Number 7, November 1995

Copyright (C) 1995 by the National Council of Teachers of English. All rights reserved. 
be to undermine its positive intellectual value, thereby obstructing rather than facilitating the learning process.

If teachers are to adopt a positive approach, they must be able to do so within the strictures of their universities' regulations on plagiarism. Those regulations, however, typically describe plagiarism in all its forms as a problem for adjudication, and this generalization leaves teachers little space for pedagogical alternatives. In typical college regulations on plagiarism (which are often grouped under headings wherein plagiarism serves as either a synonym for or a subset of "academic dishonesty"), all forms of plagiarism, including patchwriting, are located on a juridical continuum on which expulsion from college-the academic death penalty-sits at the extreme end as a potential punishment.

It is the object of this essay to suggest a plagiarism policy that would respect the textual values expressed in existing policies but that would also revise policy to allow for alternative approaches-and specifically to enable pedagogy that is responsive to contemporary theory. This new policy does not endorse a "more lenient attitude" toward plagiarism; rather, it suggests an enlarged range of definitions and motivations for plagiarism, which in turn enlarges the range of acceptable responses. Such a policy is of necessity a compromise; traditional textual values attribute proprietorship, autonomy, originality, and a corollary morality to "true" authorship, whereas a substantial sector of contemporary theory denies the very possibility of associating any of these qualities with authorship.

\section{Authorships}

It has become commonplace to assert that prior to the modern era, mimesis was the means whereby Western writers established their authority, and textual collaboration was their method of composition. The pre-modern writer did not need to cite his sources. (The masculine pronoun is well established as the only appropriate one for discussions of medieval and early modern authorship. Though women did write at that time, the male writer was plainly normative.) Robert Burton in his seventeenth-century Anatomy of Melancholy attributes to the Roman writer Lucan the now-familiar metaphorical expression of the mimetic textual economy: "A dwarf standing on the shoulders of a giant may see farther than a giant himself." Implicit in this aphorism is an emphasis on accumulated knowledge. The notion of reverence for the giants, the source, the Authority, is also explicit in the metaphor of standing on the shoulders of giants, as is an endorsement of the practice of imitating the source.

Historian Giles Constable goes so far as to declare, "The term plagiarism should indeed probably be dropped in reference to the Middle Ages, since it expresses a concept of literary individualism and property that is distinctively modern" (39). Martha Woodmansee concurs: the notion of the author as an individual 
creator of original works is a "relatively recent invention" ("Author Effect" 15). According to Mark Rose, the shift from mimetic to individualistic authorship took place in response to the technological innovation of the printing press. Widespread dissemination of texts gave rise to the possibility of making a living as a writer, unfettered by patrons. From these economic conditions arose copyright laws, beginning in England with the 1710 Statute of Anne and in the U.S. with Congressional legislation in 1790. Amplifying Rose's account of the availability and commodification of texts associated with the emergence of the individual author, Woodmansee emphasizes a third essential element: the appearance of the reader. The eighteenth century saw a dramatic increase in mass literacy in England and most of Western Europe, a commensurately greater demand for texts, and hence enhanced possibilities for the profession of writing.

That this account of authorships in the West is described in historical sequence does not amount to an antipodal chronology of authorship in which mimesis characterizes antiquity and the Middle Ages, displaced by individual, originary authorship in the modern period. Though commonly associated with the modern era, the notion of plagiarism and the concomitant possibility of individual authorship can be traced back to the ancient world. The very etymology of the word plagiarism demonstrates the antiquity of the concept: the Roman poet Martial extended the meaning of the Latin plagiarius (kidnapper) to indicate the theft of words as well as of slaves. Indeed, the history of Western letters from antiquity through the Middle Ages is punctuated by writers' complaints about their plagiarists. Significantly, the well-worn aphorism concerning giants and dwarfs or pygmies not only valorizes the source and the accumulation of knowledge but also accords to the latest writer the greatest knowledge. In what Robert Merton regards as the earliest verifiable statement of the aphorism, medieval theologian Bernard of Chartres's version, quoted in Jean Gimpel's The Catbedral Builders, includes all three elements:

We are as dwarfs mounted on the shoulders of giants, so that although we perceive many more things than they, it is not because our vision is more piercing or our stature higher, but because we are carried and elevated higher thanks to their gigantic size. (165)

The "we" of Bernard's aphorism-the most recent writer-is in possession of something new, a range of vision inaccessible to those giant sources. Embedded in the medieval mimetic economy of authorship, in other words, are essential components of the modern individual economy: the notion of the individual and the notion that he might seize something new. The author, in fact, may not be a recent invention. What Mark Rose's and Martha Woodmansee's work does establish, though, is that in the modern era a shift in emphasis has taken place. A chain of causes attendant upon the Gutenberg revolution has produced a textual economy in which the source must be resisted (consider the anxieties of influence described by Harold Bloom and Françoise Meltzer) or bracketed (in scholarly citation, which 
Constable and many others regard as legitimated plagiarism) and in which mimesis is clearly inferior to the originary compositions of the Romantic genius (Woodmansee, "Author Effect" 18). The individual author defines the post-Gutenberg playing field, and that author is credited with the attributes of proprietorship, autonomy, originality, and morality. Although three centuries after the inception of the modern author these attributes have come to be regarded as "facts" about authorship, their historical emergence demonstrates them to be cultural arbitraries, textual corollaries to the technological and economic conditions of the society that instated them.

Today the technological innovation of the computer is precipitating and accompanying shifts in textual values that may be as profound as the modern emergence of the normative autonomous, individual author. In this new textual economy, Woodmansee says that the computer is "dissolving the boundaries essential to the survival of our modern fiction of the author as the sole creator of unique, original works" ("Author Effect" 25). Peter Holland points to hypertext as one of the ways in which digitized technology destabilizes the normative individual author. In hypertext, readers make additions and changes without necessarily leaving any trace of who contributed what, and a text is never "finished." "Hypertext," Holland says, "enables us to reconsider the whole notion of the intellectual status authorship confers, not least since it creates two types of authors/editors, refusing to distinguish between the two: those who write sentences and those who restructure materials" (21). No longer do we have originators and plagiarists-or giants and pygmies-but the collective, always unfinished text. To debate whether this most recent shift-or indeed, any shift in the representation of authorship-is a "good thing" would be to postulate some sort of pre-discursive reality to textuality. It is sufficient, at least for the moment, to observe that this shift, like its predecessors, reflects and reproduces the social conditions that produced it.

\section{Plagiarisms}

Hypertext makes visible what literary critics have theorized: the cumulative, interactive nature of writing that makes impossible the representation of a stable category of authorship and hence a stable category of plagiarism. Susan Stewart brands current legal definitions of literary property as "naïve materialism" (15-16). Another critic, Françoise Meltzer, explains Descartes's and Freud's anxieties about originality: writers who want recognition must assert priority; to assert priority is to assert originality; and to assert originality engenders a fear of being robbed. Behind that fear of being robbed is "the larger fear that there is no such thing as originality" (40-41).

If there is no originality, there is no basis for literary property. If there is no originality and no literary property, there is no basis for the notion of plagiarism. 
Ellen McCracken finds in a short story by Ricardo Piglia a "metaplagiarism" that she celebrates for its challenge to literary property. And Woodmansee questions whether solitary, originary authorship has ever described how any writer composes; instead, she characterizes it as an ideal constructed and promulgated for economic purposes ("Author Effect" 15).

These scholars are working in the tradition of Roland Barthes and Michel Foucault, who describe the author as a cultural arbitrary. Pierre Bourdieu and JeanClaude Passeron offer a useful explanation of the sense in which "arbitrary" is here used:

The selection of meanings which objectively defines a group's or a class's culture as a symbolic system is arbitrary insofar as the structure and functions of that culture cannot be deduced from any universal principle, whether physical, biological or spiritual, not being linked by any sort of internal relation to "the nature of things" or any "human nature." (8)

But again, it is important to acknowledge the synchronic and diachronic complexities of representations of authorship. Mark Rose notes that it is not just poststructuralists who reject a foundational role for the autonomous author: Northrop Frye observed in 1957 that copyright obscures the conventionality of literature, the mimetic nature of composition (Rose 2). Though the individual author, promoted from pygmy to giant, took center stage in the modern textual economy, the giant sources and the accumulation of knowledge were not banished from the drama of authorship.

Keith D. Miller's scholarship, moreover, reveals that the collaborative author is the normative model in at least one contemporary American culture. In various articles and in Voice of Deliverance, Miller argues that Martin Luther King, Jr., was engaged in "voice merging"-the African-American folk preaching tradition of patching together unattributed words, phrases, and even extended passages from theological sources, the Bible, and other preachers' sermons. He attributes King's "plagiarism" (a word which, significantly, Miller himself seldom applies to King's textual strategies) to the oral traditions of King's primary community. King's composing practices originate in the oral traditions of the African-American church, where discourse is "communal wealth"; "By enlarging the pool of discourse and the size of audiences, print altered King's rhetorical universe without disturbing its premise that words are shared assets, not personal belongings" (“Composing" 79). To academic and political discourse Martin Luther King, Jr., brought textual values from the discourse of African-American folk preaching. Regardless of what he may have known about the textual values of the academy (and David J. Garrow, among others, argues energetically that King was well aware of and therefore should have adhered to academic injunctions against plagiarism), in his dissertation and speeches he engaged in what Miller describes as "voice merging." He applied the textual practices of one community to his writing in another. 
King's textual strategies reveal the multiple communities in which writers work and the resulting complexities of community allegiances. The King case illustrates Joseph Harris's assertion that no one is ever a member of just one community at a time. Perhaps none of us makes neat switches between mutually exclusive communities; instead, our communities and our allegiances to them compete with and overlap each other. We carry the practices and conventions of one community into another, as King did by engaging in African-American voice merging when composing his academic and political prose.

Neither diachronically nor synchronically, then, can authorship be bounded into stable, antipodal categories of mimetic, autonomous, or collaborative authorship. The heterogeneity of theories of authorship, the contradictory definitions that exist simultaneously, render impossible any sort of unitary representation. Yet both pedagogy and institutional policies on student authorship-and specifically, student plagiarism-attempt just that. Representations of student plagiarism seldom acknowledge the heterogeneous definitions of authorship in contemporary letters. Instead, these representations simplify student authorship, depicting it as a unified, stable field. The principle used for the task of unifying and stabilizing student plagiarism is the putative morality of the "true" (autonomous) author. Immorality in these representations is not attributed just to some plagiarists, such as those who purchase term papers. Rather, immorality attaches to the practitioners of all textual practices, including patchwriting, that are classified as plagiarism.

Such moral criteria for plagiarism seem natural and necessary, drawing as they do upon widely held assumptions. Former editor of the New York Times Magazine James Atlas attributes flagging "moral character" to those who succumb to the temptation to plagiarize, and so does Chris Raymond in his Cbronicle of Higher Education reports on Martin Luther King, Jr. In composition studies, too, plagiarism is not infrequently described as immoral. Frank J. McCormick in the fournal of Teacbing Writing talks about crime and honor; Augustus Kolich in College English about moral standards and citizenship; Elaine E. Whitaker in College Composition and Communication about academic integrity; Edward $M$. White in the Cbronicle of Higher Education about theft and "dirty secrets"; and Edith Skom in the AAHE Bulletin about crime, theft, and the plagiarist as "less of a person."

Indeed, punishing plagiarists is not infrequently described as an essential academic obligation. Drummond Rennie, an editor of the fournal of the American Medical Association, articulates an attitude familiar in the academy: "The bottom line is, if we don't take a stand on plagiarism, what the hell do we take a stand on?" (qtd. in Mooney A13). The prosecution of plagiarism, in his description, is the last line of defense for academic standards.

Informing composition studies are the textual values of individualistic authorship, which culminate in a juridical stance toward all the textual strategies that have come to be labeled as plagiarism. A wide range of composition pedagogy, notably 
that aligned with expressivism, describes writing as a way to discover and develop one's immanent beliefs. Composition instruction therefore aims to teach writing as discovery and to help writers express themselves in their own authentic language. The binary opposite of this notion-necessary, it would seem, for the notion to have meaning-is plagiarism and writers who purloin the thoughts and expressions of others.

In fact, pedagogy and scholarship that might appear to offer alternatives to individualistic notions of authorship may in fact be based on those very notions. Dramatic examples are provided by Andrea A. Lunsford and Lisa Ede, who detail the ways in which prominent scholars of collaborative learning-not only Peter Elbow but also Kenneth Bruffee-endorse the autonomous author. Lunsford and Ede charge that models for collaboration have "failed to challenge traditional concepts of radical individualism and ownership of ideas and [have] operated primarily in a traditional and largely hierarchical way" (431). Lester Faigley, though warning against "dichotomous categories" of modernism and postmodernism in composition studies, is able to say,

Where composition studies has proven least receptive to postmodern theory is in surrendering its belief in the writer as an autonomous self, even at a time when extensive group collaboration is practiced in many writing classrooms. Since the beginning of composition teaching in the late nineteenth century, college writing teachers have been heavily invested in the stability of the self and the attendant beliefs that writing can be a means of self-discovery and intellectual self-realization.

It is this notion of the "autonomous self" that renders representations of student plagiarism univocal endorsements of the Romantic genius-as evidenced in Edward M. White's statement:

Plagiarism is outrageous, because it undermines the whole purpose of education itself: Instead of becoming more of an individual thinker, the plagiarist denies the self and the possibility of learning. Someone who will not, or cannot, distinguish his or her ideas from those of others offends the most basic principles of learning.

A substantial contingent of composition scholars has, nevertheless, joined the interrogation of the autonomous author. David R. Russell's notion of learning as a collaborative rather than solitary phenomenon contrasts significantly with White's:

Learning is at bottom acquiring habits from other people, habits of activity, including communicating and thinking, which are, in the deepest sense, kinds of activity, since there is no real division between mind and body, thinking and doing. (183)

And Kathryn T. Flannery recapitulates Susan Miller:

Students are always caught "intertextually"-they are never inventing a new language out of nothing, but patch together fragments of the multiple texts, the multiple voices (as Bakhtin would put it) that are already available to them. (Flannery 707) 
Composition scholars' representations of the writer are characteristically more fissured. Kurt Spellmeyer, for example, invokes both mimetic and originary composition:

Ordinarily we refer to prose that merely restates the language of previous writers as "quotation," "paraphrase," "summary," or "plagiarism." Every writer, of course, borrows something from past achievements and must work within the historical limitations of a genre, but sheer replication is never apropos because writing addresses itself primarily to the not yet written. (18)

These statements demonstrate that composition studies, like contemporary criticism, presents anything but a unified front on issues of plagiarism and authorship. Susan Miller, Andrea Lunsford, and Lisa Ede question the autonomous author, but Thomas Mallon's trade book, Stolen Words, assumes a normative autonomous author. Although Susan Stewart's genealogy of authorship rejects it as a simplistic account of plagiarism that suffers from a lack of historical awareness of the relationship between law and literature (Stewart 30 n. 44), Stolen Words is a popular and oft-cited source among compositionists. Martha Woodmansee's and Mark Rose's work in the history and theory of authorship challenges the necessity and even the possibility of the autonomous author, but David Saunders, also working in copyright theory, dismisses Woodmansee and Rose as perpetrators of postmodern ephemera. Even collaborative composition theorists, in Lunsford and Ede's account, endorse autonomous authorship. What is happening in textual studies is not the overthrow of a post-Gutenberg paradigm by a post-Internet norm, but a shift of emphases, a shift in perspectives. These perspectives, moreover, may be mutually incompatible but may nevertheless inhabit the same space at the same time.

The dialectic of these simultaneous perspectives constitutes sufficient discipline-internal pressure upon the very notion of plagiarism to prompt its redefinition in the policies that govern student authorship-institutional policies against plagiarism. Given the contested notions of authorship in the academy today, the Romantic originator can no longer be the sole model of the author on which colleges' plagiarism policies draw. Nor, in the wake of the postmodern death of the author, can a revised (or discarded) policy declare the student writer a casualty caught in the crossfire. We must redefine institutional policies to account for the dialectic. In that dialectic we may discover phenomena of authorship that were obscured by overdetermined definitions of and legislation against plagiarism.

Redefinition is already underway not only in the realm of theory but also in commentators' fresh advice for teachers' and administrators' pedagogical responses to plagiarism. Although Margaret Kantz assumes that student papers strive to present "original arguments" (75), she believes that student plagiarism results from teachers' poor task representations (84), rather than from either of the two causes to which plagiarism is traditionally ascribed-a lack of morality or an ignorance of citation conventions (see McLeod 11). Alice Drum, too, postulates the possibility 
of students' original contributions to their essays, but at the same time she argues that the response to plagiarism should be as much pedagogical as juridical (242-43) - a sentiment apparently shared by Frank McCormick (143).

Lunsford and Ede go a bit further when they challenge the "obsession" with plagiarism engendered by "the institutional reliance on testing 'norms' and the ideology it reflects." Questioning the "formalist, positivist, and individualist ideological assumptions on which common notions of plagiarism rest," they advocate that teachers adopt a "rhetorically situated view of plagiarism, one that acknowledges that all writing is in an important sense collaborative and that 'common knowledge' varies from community to community and is collaboratively shared" (436-37).

Still other composition scholars have focused specifically on the composing practice of patchwriting. Pedagogical recommendations for preventing, responding to, or curing plagiarism typically recommend instruction in source attribution, but I have argued (as have Glynda Hull and Mike Rose, as well as Elaine Whitaker) that patchwriting may have quite a different genesis. Most writers engage in patchwriting when they are working in unfamiliar discourse, when they must work monologically with the words and ideas of a source text. As a way of helping patchwriters find a voice and gain a sense of community membership, Hull and Rose advocate a provisional "free-wheeling pedagogy of imitation" (151); and I have recommended structured collaborative summary-writing (240-43). Both their recommendations and mine are made not in order to "prevent" or "cure" patchwriting but to help students make maximum intellectual use of it and then move beyond it. These recommendations attribute positive pedagogical value to a composing strategy that has traditionally been labeled "plagiarism" and classified as academic dishonesty-a classification which would ascribe criminality to an important stage in students' learning processes, thereby thwarting learning.

The idea of positive plagiarism is hardly new; T. S. Eliot's "Philip Massinger" articulates what was then and is now a widely shared sentiment: "Immature poets imitate; mature poets steal; bad poets deface what they take, and good poets make it into something better, or at least something different" (143). What revised definitions of plagiarism acknowledge is the possibility that intentions of writers other than poets and writers of fiction might justify practices that have traditionally been classified as plagiarism and that have too readily been excoriated as a sign of the writer's immorality. Student writing must be accorded the same respect as professional writing: it must be treated as subject rather than object formation:

The concepts of author and authorship, so radically destabilized in contemporary literary theory-and in current discursive practice in fields as far removed as engineering and law-have also been problematized in the field of rhetoric and composition studies, where scholars have challenged the traditional exclusion of student writing from claims to "real writing" and "authorship," explored the ways in which autbority is experienced by student writers, and increasingly sought to map various models of composing processes. (Lunsford and Ede 417) 


\section{Formulating Institutional Policy}

By imagining positive, non-juridical definitions of and responses to textual strategies that have long been depicted in the criminal terms of plagiarism, the reports and recommendations of Drum, Howard, Hull and Rose, Kantz, McCormick, and Whitaker render impossible a unitary representation of student authorship. These challenges are, however, insufficient. The regulatory fiction of the autonomous author continues to prevail in academic prohibitions of plagiarism. Institutions' uniformly juridical policies against plagiarism restrict the extent to which pedagogy can respond to revised cultural representations of authorship. Teachers who follow the advice of Drum, Howard, Hull and Rose, Kantz, McCormick, and Whitaker might find themselves professionally compromised if their institutions' regulations provided only for juridical responses. Teachers may therefore be forced into counter-pedagogical responses; as Peter Jaszi and Martha Woodmansee point out, it is students who suffer and pay for intractable policies that are at variance with widely endorsed theories of authorship (9).

Universities' policies describe plagiarism in moral terms when they classify it as a form of "academic dishonesty." At the same time, though, these policies often define plagiarism in formalist terms, as features of texts. Plagiarism policies may even specifically exclude the writer's intentions, stipulating that plagiarism is plagiarism even if the writer is ignorant of its prohibition.

Certainly, morality is the major factor in the purchase of term papers described by Gary M. Galles, Michael Pemberton, and Edward White; and it may apply to other types of plagiarism, as well, depending upon the writer's intentions. But morality is not a necessary component of plagiarism, and ignorance of citation conventions is not its sole alternative. A third possibility, too seldom recognized, is that students may have commendable reasons for engaging in patchwriting, a textual strategy that is commonly classified as plagiarism.

A college's policy on plagiarism needs to ask the same questions about students' motivations that Stewart, Meltzer, McCracken, and Eliot ask of their professional writers. In reading students' prose, we need first to know whether the writer intended to plagiarize. If the plagiarism was intentional, we then need to know motivations: Was it for personal gain at the expense of others? In order to challenge the concept of plagiarism itself? To weave new patterns from the fabrics of others? And if the plagiarism was not intentional, we still need to know motivations: Was it engendered by an ignorance of citation conventions? By a monologic encounter with unfamiliar words and concepts?

Similarly, we must engage questions of context. Is the student experienced in the discourse of the discipline in which he or she is writing? Has the student been introduced to the textual conventions of the discipline? (Some disciplines, for example, have a considerably higher tolerance for and expectation of students' recapitulating their sources-whether in paraphrase, summary, quotation, or patch- 
writing - than do others.) Is the student working from sources assigned by the instructor? (In such cases it is unlikely that he or she intended to deceive.) Different answers to these questions should elicit different responses from the questioner. And this raises another inescapable component of plagiarism: the reader. The meaning of a text does not, in fact, reside in the text, but in the interplay of text, intertext(s), writer, social context-and reader. Linda Hutcheon asserts that plagiarism occurs only in the reader's interpretation, when "visible sources become signs of plagiarism, and influences yield to 'intertextual' echoes" (230).

Without specifying how they might be made, Lunsford and Ede (436-37) and Keith Miller ("Redefining") recommend changes in colleges' plagiarism policies. Building upon their work, the next section of this essay drafts a comprehensive institutional policy on plagiarism, a policy consonant with the conditions of contemporary intellectual life, including electronic media, an awareness of historical contingency and cultural diversity, and an attention to the social dynamics of composing.

Given the range of contemporary theories of authorship, a postmodern dismissal of all academic plagiarism policies would be unreasonable; the academy's stance on plagiarism must represent (insofar as it is possible) the dialectic, not just one voice in it. Nor is it likely that many theorists would actually want to abolish all policy on plagiarism, for very few find the purchase of term papers acceptable. It is, however, reasonable to revise definitions of plagiarism to account for the contingent nature of authorship and its constituent discourses; to account for the collaborative nature of writing; to allow authorial intention as a factor in the adjudication of student plagiarism; and to postulate positive value for patchwriting, a textual strategy that is too often classified as plagiarism, regarded as immoral, and punished by "Fs" and even expulsion.

The following plagiarism policy is institution-specific. As will be obvious, a number of changes would have to be made if it were adopted at other collegesreference to the handbook used at the institution, for example, or to the resources available at the writing center. The defining categories into which it analyzes plagiarism - the categories of cheating, non-attribution, and patchwriting-are overlapping rather than mutually exclusive; this policy does not resolve all ambiguities involved with plagiarism. Instead, it acknowledges the complexities of the issue and offers guidelines for negotiating what will continue to be contested terrain. The policy acknowledges the terms of that contest and urges all participants-writers and readers-to engage it as openly as possible.

\section{A Proposed Policy on Plagiarism}

It is perhaps never the case that a writer composes "original" material, free of any influence. It might be more accurate to think of creativity, of fresh combinations made from existing sources, or fresh implications for existing materials. 
An important requirement of most academic writing is acknowledging one's sources. We all work from sources, even when we are being creative. American academic culture demands that writers who use the exact words of a source supply quotation marks at the beginning and end of the quotation, so that the reader can know where the voice of the source begins and ends. In addition, the writer must use footnotes, parenthetical notes, or endnotes to cite the source, so that the reader can consult that source if he or she chooses. Writers must also acknowledge the sources not only of words but also of ideas, insofar as is possible, even when they are not quoting word for word. Moreover, in final-draft writing, academic writers may not paraphrase a source by using its phrases and sentences, with a few changes in grammar or word choice-even when the source is cited.

Plagiarism is the representation of a source's words or ideas as one's own. Plagiarism occurs when a writer fails to supply quotation marks for exact quotations; fails to cite the sources of his or her ideas; or adopts the phrasing of his or her sources, with changes in grammar or word choice.

Plagiarism takes three different forms-cheating, non-attribution of sources, and patchwriting:

1. Cheating Borrowing, purchasing, or otherwise obtaining work composed by someone else and submitting it under one's own name. The minimum penalty is an " $F$ " in the course; the maximum penalty, suspension from the university.

2. Non-attribution Writing one's own paper but including passages copied exactly from the work of another (regardless of whether that work is published or unpublished or whether it comes from a printed or electronic source) without providing (a) footnotes, endnotes, or parenthetical notes that cite the source and (b) quotation marks or block indentation to indicate precisely what has been copied from the source. Because non-attribution is sometimes the result of a student's inexperience with conventions of academic writing, instruction in source attribution and subsequent revision of the paper may be the instructor's most appropriate response. Non-attribution can alternatively be the result of a student's intent to deceive, in which case the minimum penalty is an " $F$ " in the course and the maximum penalty, suspension from the university.

3. Patchwriting Writing passages that are not copied exactly but that have nevertheless been borrowed from another source, with some changes-a practice which The Bedford Handbook for Writers calls "paraphrasing the source's language too closely" (477). This "patchwriting" is plagiarism regardless of whether one supplies footnotes, endnotes, or parenthetical notes that acknowledge the source. However, patchwriting is not always a form of academic dishonesty; it is not always committed by immoral writers. Often it is a form of writing that learners employ when they are unfamiliar with the words and ideas about which they are writing. In this situation, patchwriting can actually help the learner begin to understand the unfamiliar material. Yet it is a transitional writing form; it is never acceptable for final-draft academic writing, for it demonstrates that the writer does not fully understand the source from which he or she is patchwriting. Because patchwriting can result from a student's inexperience with conventions of academic writing, instruction in quotation and source attribution and a request for subsequent revision of the paper may be an appropriate response for the instructor. But because patchwriting often results from a student's unfamiliarity with the words and ideas of a source text, instruction in the material discussed in the source and a request for subsequent revision of the paper is even more frequently the appropriate response. Patchwriting can also be the result of a 
student's intent to deceive, in which case the minimum penalty is an " $F$ " in the course and the maximum penalty, suspension from the university.

\section{Additional advice for students:}

Both citation (footnotes, parenthetical notes, or endnotes) and quotation marks are required whenever you copy exact words and phrases from a source. When you paraphrase or summarize but do not copy exactly, citation is still required. When in doubt, cite; over-citation is an error, but under-citation is plagiarism. Your citations should follow a recognized style sheet; you should not make up your own system. If your instructor does not specify a style sheet, you may want to adopt the MLA style, which is described in The Bedford Handbook for Writers, $\$ 50$, or the APA system, $\$ 51$. For advice about when to quote sources, see $\$ 49 \mathrm{~d}$; and for detailed explanation of how to quote, $\$ 37$ and $49 \mathrm{e}$.

The sources you should cite include not only printed materials but also electronic sources. Most style sheets are currently publishing new editions that provide advice for citing sources obtained by computer-materials from the Internet or CD Rom disks, for example.

The sources you should cite also include contributions that others may make to your drafts in progress-friends, family, classmates, and tutors who gave you ideas for your essay or who made suggestions for its improvement. Writers customarily provide a single discursive footnote to acknowledge such contributions. Often the footnote appears at the end of the title or the first paragraph of the essay. Usually one to three sentences, naming the contributors to the paper and sketching the nature and extent of their contributions, suffice.

Patchwriting, the third type of plagiarism listed above, is an issue somewhat more complicated than that of citation. For example, a student who had never before studied theories of mythology read the following passage:

The world of the Ancient Near East, however, was familiar with myth of a rather different kind, myth as the spoken word which accompanied the performance of certain all-important religious rituals. (Davidson 11)

The student then wrote a paper that included this patchwriting:

Davidson explains ritual myths as concepts that are illustrated through spoken words but are also accompanied by the performance of religious ceremonies. (Qtd. in Howard 237)

The student deleted many phrases from the original (such as "The world of the Ancient Near East") and substituted synonyms ("ceremonies" for "rituals," for example). But the structure of the student's prose is that of Davidson, following exactly the latter half of Davidson's sentence. The student obviously did not write this passage with the intention of deceiving, for he acknowledges that these are Davidson's ideas ("Davidson explains"). The student's motivation sprang from neither a lack of morality nor an ignorance of footnoting procedures, but rather from a difficulty in understanding Davidson's text.

Patchwriting in such a situation can be an effective means of helping the writer understand difficult material; blending the words and phrasing of the source with one's own words and phrasing may have helped the student comprehend the source. But it is not an acceptable practice for public writing-for the papers that one hands 
in. Patchwriting can help the student toward comprehending the source; but patchwriting itself demonstrates that the student does not yet understand that source.

The next step beyond patchwriting - a step whereby you can come to understand the text-is effective summary: Read the source through quickly to get its general ideas, perhaps reading only the first sentence of each paragraph. Then re-read, more slowly. Go through it a third time and take notes. Then let some time elapse-a half hour should be enough-and with the book closed, write your own summary of it. (Never try to summarize or paraphrase a source while looking at that source.) With the book closed, what you write will be in your own words and sentences. Once you have drafted your summary, go back to the book and check to see if any of your phrasing resembles that of the source; if so, quote it exactly. Provide page citations for both your paraphrases and for quotations. Also, check your version to see what you forgot; what you forgot is usually what you didn't understand. Now it is time to visit your instructor for additional help in understanding the material. But you must never let yourself fall into patchwriting as a substitute for understanding the material.

Additional advice for faculty:

An instructor who suspects that a student has committed plagiarism should inform the Dean of Students. But faculty must be attentive to the complexities of plagiarism, for often a pedagogical rather than judicial response is appropriate. Patchwriting, for example, though unacceptable for final-draft academic writing, is a technique that learners typically employ in their early encounters with unfamiliar discourse. Because patchwriting represents a blend of the learner's words and phrases with those of the source, it is a valuable strategy for helping the learner appropriate and learn to understand unfamiliar words and ideas. Most patchwriters, far from being immoral members of the academic community, are instead people working their way through cognitive difficulties. The instructor can help in this process by making clear that patchwriting will not suffice for finished academic prose. Even more importantly, the instructor can aid the student in understanding the materials that are presenting such challenges. Once the student feels comfortable with those materials, he or she will probably be able to write about them with greater ease.

Most importantly, the instructor can help the student learn methods for reading and writing about difficult texts. Summarizing texts without simultaneously looking at those texts is an invaluable academic skill. Students should learn that the wrong question to ask is "How else can I say this?" Instead, they should learn to read until they understand; then write without looking at the source; and then return to the source to check accuracy and comprehensiveness and to see if any passages are sufficiently similar that they should quote them exactly.

The Writing Center can support this instructional endeavor by conducting workshops on reading and writing from sources; by supplying instructors with handouts on summary-writing; and by providing tutoring for individuals or small groups of students. Instructors can call the director of the center to arrange for workshops, ask for handouts, or refer students for appropriate tutoring.

Finally, faculty should be alert to the possibility that students may not be attributing sources or may be patchwriting because of their own cultural traditions. Students from some non-Western societies, for example-as well as those from some Western subcultures-may have been taught to adopt the voice of an authoritative source or to blend the voice of that source with their own, without citing it. The 
instructor can help students realize that expectations of attribution-and non-attribution-are culture-specific. The instructor can also assist students not only in learning the "rules" of Western academic culture but also in engaging the often slow process of becoming experienced in writing according to Western academic conventions.

\section{The Constituencies of the Academy}

Institutional policies must be centrist; they must describe the multiplicity of beliefs in the community which they purport to represent and protect. We must revise universities' plagiarism policies because at present they describe only one notion of authorship, the unified, autonomous subject whose textual manifestation derives from his or her moral turpitude. But we must not simply replace one prescriptive metanarrative with another, the individual with the collaborative. Rather, we must articulate policy that acknowledges both; for both prevail in the contemporary academy. The policy offered in the preceding section of this essay does not prescribe a subject-or an absence of one-but instead describes a variety of his or her possible textual locations. It affirms the possibility of individual authorship and hence of plagiarism, but it does not characterize plagiarism as the binary opposite of originality nor as a transgression against textual virtue. Rather, it defines plagiarism in both positive and negative terms. The negative terms are couched not in the language of morality but instead speak of a failure to recognize and acknowledge the collaborative nature of one's writing. The positive terms-heretofore absent from institutions' policies-would enhance colleges' and universities' educational agendas by sanctioning rather than criminalizing an important stage of students' learning processes.

Consonant with traditional plagiarism policies, this one resorts to features of text to differentiate its categories of plagiarism. But, consonant with contemporary theory, it adds the variables of writer, context, and reader to differentiate the two major categories of plagiarism: that which should be treated as an offense and that which should be regarded as a valuable transitional composing strategy.

Such a policy, institutionalized in its entirety-including the sections of advice to students and teachers (though these passages might best be presented in student handbooks and faculty guides, rather than in the college's canon of juridical regulations) - does not work against but enables the transformations in pedagogy that are already underway in the classrooms of practitioners like Hull and Rose. It acknowledges plagiarism as a cultural arbitrary and urges faculty not to be overly zealous in their response to the manifestation of alternative textual values in the work of students from non-Western or non-mainstream cultures.

What this policy does not and cannot do is provide for the future effects of electronic composition. The policy is itself provisional, and it will need to be revised again in a very few years. The free-form collaborations that are already 
occurring on the Internet have caused a considerable stir. Participants in discussion groups complain about their remarks' being cited without their permission, and the net proposes that participants respect their colleagues by obtaining such permissions. Reaching an impasse while writing a book, essay, or paper, a discussion group participant poses the problem on the net and receives a variety of responses, some from anonymous members; and these responses, impossible to trace, become part of the writer's thinking. Recommendations are being formulated for revising copyright law to account for electronic media. Richard Lanham's book on authorship in cyberspace is published simultaneously in hard copy and on computer disk. University publishers anticipate offering all their books in electronic media. Academic journals are published in cyberspace, and discussion about them proliferates in the same medium. The Internet user surfs through a universe of information, stumbling quite by accident upon all sorts of materials without knowing quite how he or she got there or how to get home again. Citing data from such sources can pose near-impossible challenges for the writer. And when any of these phenomena occur in hypertext, with its multiple authors whose contributions are untraceable, the matter becomes hopelessly entangled.

These and many other aspects of electronic composition (not least of which are the questions of censoring the net and ensuring that writers of electronic texts will be able to reap monetary profits from their endeavors) promise to transform the nature of authorship in the twenty-first century. Because we are at present riding the early wave of this change, we cannot yet describe what authorship will look like in fifty years, much less account for it in present-day policy regarding student plagiarism.

We can, however, address the issues that are already established regarding student writing and focus on the task of enabling the innovative pedagogical approaches already suggested by composition scholars, while recognizing that whatever determinations we reach are necessarily provisional. Jaszi and Woodmansee say that the pressures on the economy of authorship have not yet caused revision of juridical installations regarding copyright and plagiarism; if anything, these have become even more strident in defense of textual purity (8-9). Observing the chasm between theory and the law, we must recognize that pedagogical applications of contemporary theory have gone as far as they can within the limits of now-outdated law. It is time, therefore, to undertake gradual revisions of the law, so that it will reflect rather than obscure the complexities of student authorship.

\section{Works Cited}

Atlas, James. "When an Original Idea Sounds Really Familiar." New York Times. 28 July 1991: 4:2. 
Barthes, Roland. "The Death of the Author." Image, Music, Text. Ed. and trans. Stephen Heath. New York: Hill and Wang, 1977.

Bloom, Harold. The Anxiety of Influence: A Theory of Poetry. New York: Oxford UP, 1973.

Bourdieu, Pierre, and Jean-Claude Passeron. Reproduction in Education, Society and Culture. Trans. Richard Nice. 1977. Newbury Park, CA: Sage, 1990.

Constable, Giles. "Forgery and Plagiarism in the Middle Ages." Archiv für Diplomatik, Schriftgeschichte, Siegel- und Wappenkunde 29 (1983): 1-41.

Davidson, Robert. Genesis 1-11. Cambridge: Cambridge UP, 1973.

Drum, Alice. "Responding to Plagiarism." College Composition and Communication 37 (May 1986): 241-43.

Eliot, T. S. "Philip Massinger." Essays on Elizabethan Drama. New York: Harcourt, Brace, \& World, 1932. 141-61.

Faigley, Lester. Fragments of Rationality: Postmodernity and the Subject of Composition. Pittsburgh: U of Pittsburgh P, 1992.

Flannery, Kathryn T. "Composing and the Question of Agency." College English 53.6 (October 1991): 701-13.

Foucault, Michel. The Order of Things: An Archeology of the Human Sciences. New York: Vintage, 1973.

- "What Is an Author?" Language, Countermemory, Practice: Selected Essays and Interviews. Ed. Donald F. Bouchard. Trans. Donald F. Bouchard and Sherry Simon. Ithaca: Cornell UP, 1977. 113-38.

Galles, Gary M. "Professors Are Woefully Ignorant of a Well-Organized Market Inimical to Learning: The Big Business in Research Papers." Chronicle of Higher Education 28 October 1987: B1, B3.

Garrow, David J. "King's Plagiarism: Imitation, Insecurity, and Transformation." Journal of American History 78 (June 1991): 86-92.

Gimpel, Jean. The Cathedral Builders. Trans. Carl F. Barnes, Jr. New York: Grove, 1961.

Hacker, Diana. The Bedford Handbook for Writers. 4th ed. Boston: Bedford, 1994.

Harris, Joseph. "The Idea of Community in the Study of Writing." College Composition and Communication 40 (1989): 11-22.

Holland, Peter. "Authorship and Collaboration: The Problem of Editing Shakespeare." The Politics of the Electronic Text. Ed. Warren Chernaik et al. Oxford: Office for Humanities Communication, 1993. 17-24.

Howard, Rebecca Moore. “A Plagiarism Pentimento." Journal of Teaching Writing 11.3 (Summer 1993): 233-46. 
Hull, Glynda, and Mike Rose. "Rethinking Remediation: Toward a Social-Cognitive Understanding of Problematic Reading and Writing." Written Communication 6.2 (1989): 139-54.

Hutcheon, Linda. "Literary Borrowing . . . and Stealing: Plagiarism, Sources, Influences, and Intertexts." English Studies in Canada 12 (1986): 229-39.

Jaszi, Peter, and Martha Woodmansee. Introduction. Woodmansee and Jaszi 1-13.

Kantz, Margaret. "Helping Students Use Textual Sources Persuasively." College English 52 (January 1990): 74-91.

Kolich, Augustus M. "Plagiarism: The Worm of Reason." College English 45 (February 1983): 141-48.

Lanham, Richard. The Electronic Word: Democracy, Technology, and the Arts. Chicago: U of Chicago P, 1994.

Lunsford, Andrea A., and Lisa Ede. "Collaborative Authorship and the Teaching of Writing." Woodmansee and Jaszi 417-38.

Mallon, Thomas. Stolen Words: Forays into the Origins and Ravages of Plagiarism. New York: Ticknor and Fields, 1989.

McCormick, Frànk. "The Plagiario and the Professor in Our Peculiar Institution." Journal of Teaching Writing 8 (Fall/Winter 1989): 133-45.

McCracken, Ellen. "Metaplagiarism and the Critic's Role as Detective: Ricardo Piglia's Reinvention of Roberto Arlt." PMLA 106.5 (October 1991): 1071-82.

McLeod, Susan H. "Responding to Plagiarism: The Role of the WPA." WPA: Writing Program Administration 15.3 (Spring 1992): 7-16.

Meltzer, Françoise. Hot Property: The Stakes and Claims of Literary Originality. Chicago: U of Chicago P, 1994.

Merton, Robert K. On the Shoulders of Giants: A Shandean Postscript. New York: Free P, 1965.

Miller, Keith D. “Composing Martin Luther King, Jr." PMLA 105.1 (January 1990): 70-82.

- "Redefining Plagiarism: Martin Luther King's Use of an Oral Tradition." Cbronicle of Higher Education 20 January 1993: A60.

- Voice of Deliverance: The Language of Martin Lutber King, 7 r. and Its Sources. New York: Free P, 1992.

Miller, Susan. Rescuing the Subject: A Critical Introduction to Rbetoric and the Writer. Carbondale: Southern Illinois UP, 1989.

Mooney, Carolyn J. “Critics Question Higher Education's Commitment and Effectiveness in Dealing with Plagiarism." Cbronicle of Higher Education 12 February 1992: A13, A16. 
Pemberton, Michael. "Threshold of Desperation: Winning the Fight Against Term Paper Mills.” The Writing Instructor 11.3 (Spring/Summer 1992): 143-52.

Raymond, Chris. "Allegations of Plagiarism Alter Historians' Views of Civil-Rights Leader." Chronicle of Higher Education 10 July 1991: A5, A9.

—. "Discovery of Early Plagiarism by Martin Luther King Raises Troubling Questions for Scholars and Admirers." Cbronicle of Higher Education 21 November 1990: A1, A8.

Rose, Mark. Authors and Owners: The Invention of Copyright. Cambridge: Harvard UP, 1993.

Russell, David R. "Vygotsky, Dewey, and Externalism: Beyond the Student/Discipline Dichotomy." Fournal of Advanced Composition 13.1 (Winter 1993): 173-98.

Saunders, David. Authorship and Copyright. New York: Routledge, 1992.

Skom, Edith. "Plagiarism: Quite a Rather Bad Little Crime." AAHE Bulletin October 1986: 3-7.

Spellmeyer, Kurt. "Being Philosophical about Composition: Hermeneutics and the Teaching of Writing." Into the Field: Sites of Composition Studies. Ed. Anne Ruggles Gere. New York: Modern Language Association, 1993. 9-29.

Stewart, Susan. Crimes of Writing: Problems in the Containment of Representation. New York: Oxford UP, 1991.

Whitaker, Elaine E. "A Pedagogy to Address Plagiarism." College Composition and Communication 44.4 (December 1993): 509-14.

White, Edward M. "Too Many Campuses Want to Sweep Student Plagiarism Under the Rug." Cbronicle of Higher Education 24 February 1993: A44.

Woodmansee, Martha. The Autbor, Art, and the Market: Rereading the History of Aesthetics. New York: Columbia UP, 1994.

_. "On the Author Effect: Recovering Collectivity." Woodmansee and Jaszi $15-28$.

Woodmansee, Martha, and Peter Jaszi, eds. The Construction of Authorship: Textual Appropriation in Law and Literature. Durham: Duke UP, 1994. 